\title{
STUDY OF THE ORIENTATION OF AXIAL AMINO-LIGANDS IN SOME Co(III) DIOXIMATES
}

\author{
Andrei Rija*, Eduard Coropceanu \\ Institute of Chemistry, Academy of Sciences of Moldova, 3, Academiei str., Chisinau MD-2028, Republic of Moldova \\ *e-mail: andreirija@yahoo.com
}

\begin{abstract}
A comparative study of the orientation of the axial ligands relative to the equatorial plane in $\mathrm{Co}(\mathrm{III})$ $\alpha$-dioximates was performed. $\operatorname{Co}(\mathrm{III}) \alpha$-dioximates obtained by us and those founded in Cambridge data base have been selected for this study. As a result of this study it was observed that anions from the external sphere and the solvent molecules contribute to the orientation of the axial ligands, such as thiocarbamide and selenourea. For the ligands such as aniline and sulfanilamide it is more advantageous the almost parallel orientation, when $\pi-\pi$ interactions between the aromatic rings of the ligand and metallocycle of the equatorial plane are formed. Solvent molecules such as water can be found in the crystal structure in the vicinity of thiocarbamide and selenourea ligands, which are oriented parallel to the equatorial plane. In the case when diphenylglyoxime is located in the equatorial plane, water can be found in the vicinity of parallel and perpendicularly oriented ligands. The molecules within the crystal are arranged so closely that there are no gaps in the crystal lattice of these compounds.
\end{abstract}

Keywords: $\mathrm{Co}(\mathrm{III})$ dioximates, fluorine containing anions, ligands orientation, H-bonds, biostimulation properties.

\section{Introduction}

The use of ligands containing oxime functionalities creates prerequisites for assembling of coordination compounds with diverse composition and architecture: monooxime ligands are widely used for clusters synthesis $[1,2]$ and compounds with polymeric structure [2,3]; dioxime ligands are often used for the synthesis of mononuclear compounds [4]. However, due to their ability to coordinate both through the nitrogen and the oxygen atoms of the oxime group, it is possible to obtain heteronuclear complexes as well [5]; by combining IIB group metals with some dioxime molecules coordination polymers have been obtained [6]; polyoxime ligands are used for the synthesis of poly- and heteronuclear compounds [7].

Transition metal compounds with chelate ligands have an important place in coordination chemistry. Dioximates of transition metals also belong to this class. The coordination ability of $\alpha$-dioximes to $d$-metals have received considerable attention not only from the perspective of synthesis of $B_{12}$ vitamin models or hemoglobin [8], but as well as substances that feature a broad spectrum of synthetic, analytical and structural possibilities. Dioximes can be used as catalysts in industrial processes [9], stimulators of erythropoetic functions [10], antihypoxanth drugs [11], antidote properties [12], as basis for the obtaining of new semiconductors [13], for the separation and purification of metal generating complexes, etc. It has been found that some dioximes play the role of a bridging ligand in the systems of iron complexes [14]. It should be mentioned that in this role, the dimethylglyoxime molecule has a trans configuration, as in the free crystalline dimethylglyoxime.

The diversity of transition metal dioximates is represented by the mono- and polynuclear, heteronuclear compounds with di- and polymeric structures etc. Mononuclear dioximates are well known compounds with a high stability, on the strength of pseudo-metalocycles formed by coordination of monoanionic dioximes in the equatorial plane stabilized by intramolecular hydrogen bonds between oxime groups. The synthesis of different types of heteronuclear dioximates has been performed subsequently $[15,16]$, and showed a various capacity of transition metals to coordinate to oxime group (through nitrogen or oxygen atoms). A particular interest in the field of molecular design and obtaining of complexes with various compositions has clathrochelated tris-dioximates of some transition metals [17]. The dioximates of transition metals have a highly stable $\mathrm{M}(\mathrm{DioxH})_{2}$ moiety and only 1,6 positions of octahedron give the possibility of manipulation of diverse apical ligands of various nature. Depending on the specific ligands functional groups, there might appear diverse interactions which are able to influence their apical orientation. The utilization of bridging ligands gives de possibility to assemble the complexes with di- and polymeric structures [18]. The interactions that may influence the orientation of axial ligands could arise due to equatorial ligands either, which are endowed with various functional groups. The synthesis of new dioximes with diverse functional groups, which gives new possibilities for molecular composition and structural architectures, is one of the perspective directions in this field [19].

Nowadays the researches are focused on the relationship between the composition, structure of complexes and their biological activity. The factors that influence the architecture of molecular design are studied, and a series of stability of the complexes as a function of atom donor features of the apical ligand of cation complex are trying to 
be found. The thermal stability and the decomposition process of $\mathrm{Co}(\mathrm{III})$ dioximates which contain thiocarbamide (Thio) and selenourea (Seu) have been studied by Ablov A.V. et al. [20]. It has been established that the decomposition of these compounds is followed by a series of exothermic effects. The comparison of thermal stability showed that dioximates which contain thiocarbamide in the apical position are more stable, as example for $\left[\mathrm{Co}(\mathrm{DH})_{2}(\mathrm{Thio})_{2}\right] \mathrm{NO}_{3}$, where $\mathrm{DH}$ is the monoanion of dimethylglyoxime, thermal decomposition starts at a temperature of $\sim 50^{\circ} \mathrm{C}$ higher than for $\left[\mathrm{Co}(\mathrm{DH})_{2}(\mathrm{Seu})_{2}\right] \mathrm{NO}_{3}$.

The inclusion of fluorine ions or its anion complexes in cobalt dioximates allowed the highlighting of the possibilities of unusual packing comparing with other halogenated complexes. The study of Co(III) dioximates with polyfluorine anions showed that the last ones influence the orientation of some apical ligands of the complex cations, and the large number of fluorine atoms able to form a hydrogen bonds network increase the stability of these complexes due to their supramolecular systems formed on the basis of these bonds. The inclusion of organic molecules as ligands in metal complexes can essentially modify their activity, assigning them effective biological properties. As a result of the biological tests, in which fluorine containing $\mathrm{Co}$ (III) dioximates was added to the nutrient medium of microorganisms, it was established that they act as biostimulators in the biosynthesis of vitamin $\mathrm{B}_{12}$ by Spirulina platensis cyanobacteria [21]. These studies created prerequisites to initiate the synthesis of producing synthetic analogues of natural systems, simulating the biological functions and achievement the processes which occur in these systems. Recent investigations have demonstrated that in $\mathrm{Co}(\mathrm{III})$ dioximates, the anions from the external sphere play an important role regarding the chemical and biological properties, and represent an important factor in packing of the crystal components in the complexes [22-24]. Due to the high electronegativity of the fluorine atom, strong hydrogen bonds with crystallization water molecules and $\mathrm{NH}_{2}$ groups [the case of complex cations which possess apical ligands, which contain such groups as Thio, Seu, sulfanilamide (Sam)] are formed, leading to assembly of supramolecular assemblies, which influence directly the stability of these complexes. The anion from the external sphere may influence, as well, the orientation of apical molecules.

\section{Results}

Schrauzer et al. [25] have observed that benzyl cobalamines undergo a more rapid decomposition than neopentyl fragment in solution and this fact is not exclusively due to steric reasons; there are other forces which make the $\mathrm{Co}-$ benzyl bond weaker. A study of compounds design has shown that benzyl cobaloximes behave differently in comparison with alkyl cobaloximes. The difference in reactivity is due to some interactions between benzyl group and dioxime, and these interactions are missing in alkyl groups [26]. Many recent studies were concentrated on the structural and spectral properties, intensively using the NMR method for this purpose $[27,28]$. In the majority of cobaloxime complexes, the signal for the DH methyl groups appears as a singlet at $\sim 2.0 \mathrm{ppm}$ in the ${ }^{1} \mathrm{H}$ NMR spectra, which indicates the chemical equivalence of all four methyl groups. However, a non-equivalence has been observed in a few cases, when any of the axial ligand is chiral: $\mathrm{Me}(\mathrm{CN}) \mathrm{CHCo}(\mathrm{DH})_{2} \mathrm{Py}$ and $\mathrm{MeCo}(\mathrm{DH})_{2} \mathrm{NH}(\mathrm{Me})-\mathrm{CH}_{2} \mathrm{Ph}$ [29]. A fast rotation of the $\mathrm{Co}-\mathrm{C}$ bond produces two sets of diastereomers, to show the DH methyl groups at a 1:1 ratio. Recently, there were found some complexes that have nonequivalent $\mathrm{DH}(\mathrm{Me})$ protons; for example nonequivalence results in a hindered rotation of axial 2-aminopiridine ligand in $\mathrm{CF}_{3} \mathrm{CH}_{2} \mathrm{Co}(\mathrm{DH})_{2}\left(2-\mathrm{NH}_{2} \mathrm{Py}\right)$, caused by $\mathrm{H}$-bonding of the $\mathrm{NH}_{2}$ group to $\mathrm{O}-\mathrm{H} \cdots \mathrm{O}$ bridges of the $\mathrm{DH}$ ligand [30]. In a similar way, a hindered rotation of 2-fluorocyclohexyl around $\mathrm{Co}-\mathrm{C}$ in 2-fluorocycloalkylcobaloxime causes nonequivalence and DH methyl groups appear as two signals in a 1:1 ratio [31].

Mandal et al. [32] have studied a few important questions regarding the orientation of the axial ligands in cobaloximes: what is the origin of hindered rotation of the $\mathrm{Co}-\mathrm{C}$ or $\mathrm{C}-\mathrm{Ph}$ bond? Is there any conclusive evidence to show that the hindered rotation is partly due to an interaction of aromatic ring $\pi$-electrons with the dioxime ring current? What is the role of the 2-substituent; does it have any direct interaction with the dioxime or $\mathrm{CH}_{2}$ protons or does it simply affect the electron density in the aromatic ring? In order to rationalize the above questions and to understand the role of the 2-substituent, they have undertaken ${ }^{1} \mathrm{H}$ NMR studies for $2-\mathrm{X}_{-} \mathrm{C}_{6} \mathrm{H}_{4} \mathrm{CH}_{2} \mathrm{Co}$ (dioxime) ${ }_{2} \mathrm{Py}$. In this case, the substituent $\mathrm{X}$ has been chosen such that it varies in steric size and in electron donation/withdrawal capacity. Results have shown that the 2-Ph group affects the chemical shift. The 2-substituent contributes to the total electron density in the benzyl group that interacts with the dioxime protons, and the chemical shift of dioxime protons follows the electronic effect of the 2-substituent. The nature of the substituent at the 2-position as well the electron density in the dioxime affects the extent of nonequivalence.

Anions from the external sphere of the studied compounds are rich in electronegative atoms which participate to the formation of hydrogen bonds $\mathrm{N}-\mathrm{H} \cdots \mathrm{F}, \mathrm{O}-\mathrm{H} \cdots \mathrm{F}$ and even $\mathrm{C}-\mathrm{H} \cdots \mathrm{F}$, therefore, they represent a great interest for the research of their influence on the orientation of the axial ligands. In this study we have been examined fluorinecontaining anions with different charges as well as complexes which do not contain fluoride anions. 


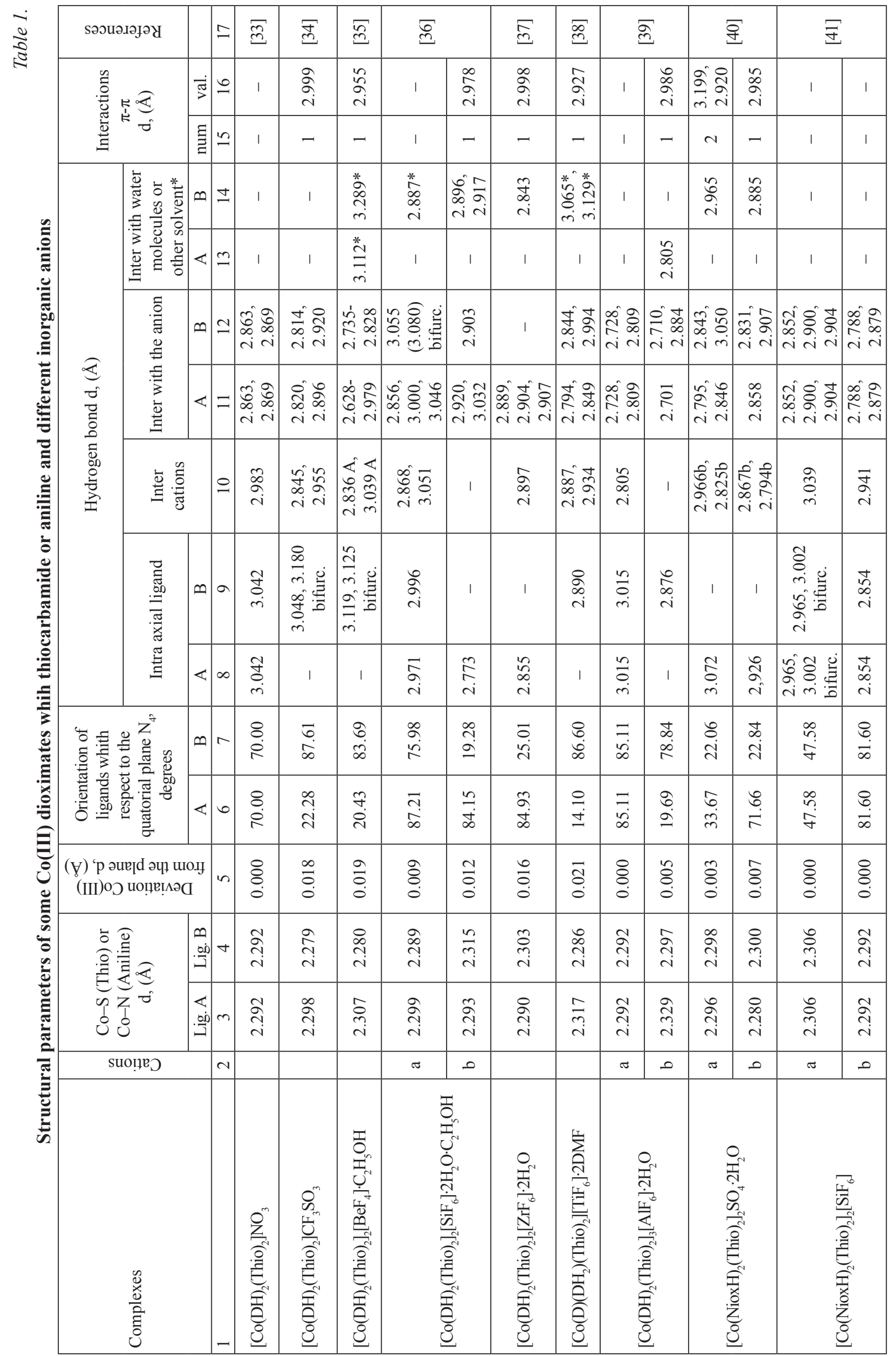




\begin{tabular}{|c|c|c|c|c|c|c|c|c|c|c|c|c|c|c|c|c|}
\hline \multicolumn{2}{|c|}{ g } & \multicolumn{2}{|l|}{$\underset{ల}{\infty}$} & \multicolumn{2}{|c|}{ 등 } & \multicolumn{2}{|c|}{$\stackrel{\varpi}{\approx}$} & \multicolumn{2}{|c|}{$\underset{ల}{\infty}$} & \multicolumn{2}{|r|}{$\stackrel{g}{g}$} & 寻 & 寻 & 守 & 导 & 导 \\
\hline 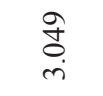 & बे & 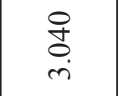 & $\begin{array}{l}\stackrel{2}{a} \\
\text { i } \\
\text { in }\end{array}$ & $\underset{\dot{m}}{\stackrel{7}{c}}$ & बे & I & I & I & I & I & $\frac{\vec{m}}{m}$ & 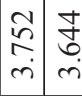 & 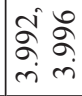 & $\begin{array}{l}\infty \\
\vdots \\
+ \\
+\end{array}$ & 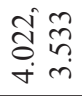 & $\begin{array}{l}0 \\
\text { ర్ } \\
\text { ri }\end{array}$ \\
\hline- & - & - & - & - & - & 1 & I & 1 & 1 & I & - & \begin{tabular}{l|l}
$N$ & $N$
\end{tabular} & $\sim$ & $\sim$ & $N$ & $N$ \\
\hline 1 & $\frac{m}{a}$ & $\begin{array}{l}\infty \\
\infty \\
\infty \\
i\end{array}$ & 1 & 1 & $\begin{array}{l}\infty \\
\stackrel{\leftrightarrow}{i}\end{array}$ & 1 & 1 & $\begin{array}{l}\overline{\vec{D}} \\
\dot{i}\end{array}$ & 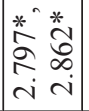 & 1 & 1 & I & $\begin{array}{l}\stackrel{P}{\infty} \\
\substack{i \\
i}\end{array}$ & 1 & 1 & $\stackrel{0}{a}$ \\
\hline $\begin{array}{l}\infty \\
\stackrel{\infty}{\infty} \\
i\end{array}$ & 1 & 1 & 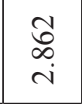 & ๙े & 1 & $\begin{array}{l}\text { ț } \\
\text { ì }\end{array}$ & 1 & 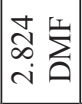 & 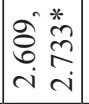 & I & 1 & $\left|\begin{array}{l}\hat{S} \\
i \\
i\end{array}\right|$ & 1 & 1 & 1 & $\frac{0}{a}$ \\
\hline $\begin{array}{l}\vec{f} \\
\stackrel{i}{i}\end{array}$ & $\begin{array}{lll}0 & 0 \\
0 & 0 \\
0 & 0 \\
i & \infty & \\
i & \end{array}$ & 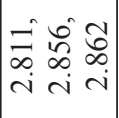 & 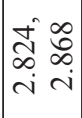 & $\stackrel{\substack{n \\
i}}{i}$ & 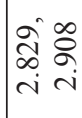 & $\begin{array}{l}\bar{\sigma} \\
\dot{r}\end{array}$ & $\begin{array}{l}\tilde{n} \\
\hat{i}\end{array}$ & 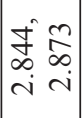 & d & 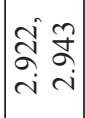 & 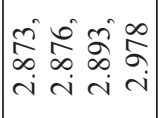 & 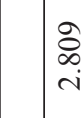 & 1 & $\underset{\sigma}{\tilde{m}}$ & $\begin{array}{l}\hat{\delta} \\
\text { iे }\end{array}$ & $\stackrel{\widetilde{\sigma}}{\vec{m}}$ \\
\hline 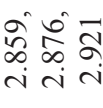 & $\begin{array}{ll}i & 1 \\
\infty & \infty \\
\infty & \infty \\
i & 0\end{array}$ & $\begin{array}{l}\stackrel{1}{\infty} \\
\stackrel{i}{i}\end{array}$ & $\begin{array}{ll}\dot{0} & \infty \\
\infty & \frac{\infty}{a} \\
i & i\end{array}$ & 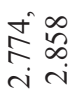 & 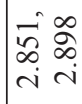 & ì & 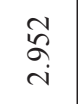 & $\left|\begin{array}{ll}n & 0 \\
& 0 \\
& 0 \\
i & i\end{array}\right|$ & $\left|\begin{array}{ll}\infty & \multirow{2}{*}{} \\
0 & \vdots \\
i & i\end{array}\right|$ & 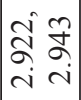 & 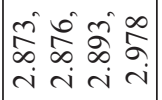 & $1 \mid \begin{array}{l}\stackrel{o}{d} \\
\infty \\
i\end{array}$ & $\begin{array}{l}n \\
i \\
i \\
i\end{array}$ & $\frac{\sigma}{\sigma}$ & $\begin{array}{l}\mathscr{a} \\
\grave{i}\end{array}$ & $\frac{\check{\sigma}}{\dot{m}}$ \\
\hline 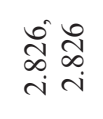 & 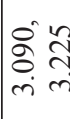 & 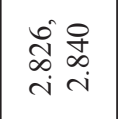 & ثे & 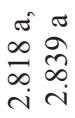 & 1 & 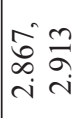 & 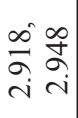 & 1 & 1 & a & 1 & $\mid$ & 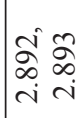 & $\begin{array}{l}0 \\
\stackrel{0}{a} \\
\text { i }\end{array}$ & 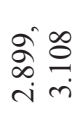 & 1 \\
\hline $\begin{array}{l}\text { ळి } \\
\stackrel{\text { సे }}{ }\end{array}$ & 1 & 1 & 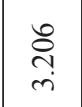 & $\frac{2}{a}$ & I & $\begin{array}{l}\text { aे } \\
\text { iे }\end{array}$ & $\begin{array}{c}\hat{\infty} \\
\text { aे } \\
\text { in }\end{array}$ & $\begin{array}{l}\vec{\infty} \\
\text { iे } \\
i\end{array}$ & $\begin{array}{l}\tilde{a} \\
\text { in }\end{array}$ & $\left|\begin{array}{cc}0 & 0 \\
0 & 0 \\
i & \dot{n}\end{array}\right|$ & 1 & \begin{tabular}{|l|l|l|l|} 
& 1
\end{tabular} & 1 & 1 & 1 & 1 \\
\hline 1 & $\stackrel{\infty}{\stackrel{\infty}{\infty}}$ & ĭ & I & 1 & $\begin{array}{l}\infty \\
\stackrel{\infty}{\infty} \\
i \\
i\end{array}$ & $\hat{a}$ & $\begin{array}{l}\infty \\
\dot{\infty} \\
i\end{array}$ & $\begin{array}{l}\hat{\widehat{o}} \\
\dot{m}\end{array}$ & 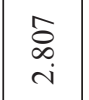 & 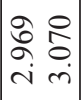 & I & 1 & 1 & 1 & 1 & 1 \\
\hline ڤે & $\frac{n}{\dot{m}}$ & 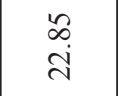 & $\begin{array}{l}0 \\
0 \\
0\end{array}$ & $\begin{array}{l}\infty \\
\mathbb{\delta} \\
\text { b }\end{array}$ & $\stackrel{q}{i}$ & 年 & $\begin{array}{l}0 \\
\stackrel{9}{+} \\
\dot{+}\end{array}$ & बे & 웅 & $\begin{array}{l}\infty \\
\infty \\
i n \\
n\end{array}$ & $\underset{\substack{\infty \\
\infty \\
m}}{\infty}$ & 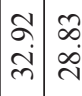 & $\begin{array}{l}\vec{\infty} \\
i \\
i\end{array}$ & $\hat{\bar{m}}$ & 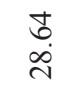 & $\stackrel{\circ}{\stackrel{1}{i}}$ \\
\hline 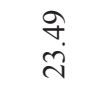 & $\stackrel{\circ}{\grave{n}}$ & $\frac{\infty}{\infty}$ & $\begin{array}{l}\stackrel{\infty}{\infty} \\
\dot{\sim}\end{array}$ & $\begin{array}{l}n \\
m \\
i \\
i\end{array}$ & $\stackrel{2}{\stackrel{2}{\Sigma}}$ & $\begin{array}{l}\hat{b} \\
\text { i }\end{array}$ & $\begin{array}{l}0 \\
\stackrel{9}{+} \\
\stackrel{+}{+}\end{array}$ & $\stackrel{\overbrace{}}{\stackrel{F}{\sigma}}$ & $\begin{array}{l}0 \\
\substack{\infty \\
\infty \\
\infty}\end{array}$ & $\begin{array}{l}\infty \\
\infty \\
i n \\
i n\end{array}$ & $\underset{\substack{\infty \\
\infty \\
\infty}}{\infty}$ & 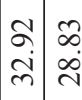 & 吾 & $\frac{\hat{\sigma}}{m}$ & $\begin{array}{l}\text { cे } \\
\dot{m}\end{array}$ & $\begin{array}{l}\stackrel{\circ}{i} \\
\text { m }\end{array}$ \\
\hline 旾 & $\stackrel{0}{0}$ & 告 & $\begin{array}{l}\hat{8} \\
\stackrel{0}{\circ}\end{array}$ & $\stackrel{\infty}{\stackrel{\infty}{0}}$ & $\stackrel{\circ}{\circ}$ & $\overrightarrow{\ddot{8}}$ & $\stackrel{8}{\circ}$ & $\begin{array}{l}\text { to } \\
\stackrel{0}{0}\end{array}$ & $\stackrel{a}{0}$ & ¿े & $\stackrel{8}{\circ}$ & 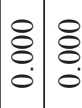 & $\overrightarrow{\overline{0}}$ & \begin{tabular}{l}
8 \\
\hdashline \\
\hdashline
\end{tabular} & $\begin{array}{l}\text { ठै. } \\
\text {. }\end{array}$ & $\stackrel{8}{8}$ \\
\hline$\underset{\substack{i \\
i}}{\stackrel{8}{2}}$ & 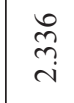 & 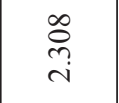 & તે & 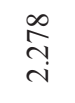 & $\frac{\stackrel{0}{m}}{i}$ & 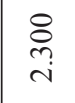 & $\begin{array}{l}\overrightarrow{\overrightarrow{0}} \\
\underset{i}{i}\end{array}$ & $\begin{array}{l}\text { ర్ } \\
\text { ì }\end{array}$ & 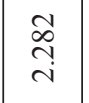 & $\begin{array}{l}\text { ते } \\
\text { iे }\end{array}$ & 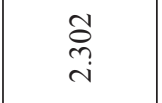 & 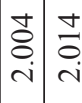 & $\underset{\vec{c}}{\vec{i}}$ & $\overrightarrow{\vec{\Delta}}$ & $\begin{array}{l}\stackrel{\Delta}{\Delta} \\
\text { i }\end{array}$ & $\overrightarrow{\bar{\sigma}}$ \\
\hline$\frac{\infty}{m}$ & 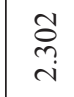 & तิ & $\begin{array}{l}\vec{N} \\
\vec{i}\end{array}$ & ते & ત્તે & 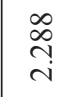 & $\begin{array}{l}\vec{\infty} \\
\stackrel{N}{N} \\
\vec{i}\end{array}$ & 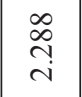 & 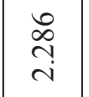 & $\begin{array}{l}\text { ते } \\
\text { ते }\end{array}$ & 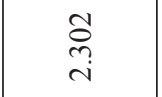 & 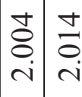 & 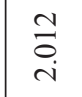 & $\overrightarrow{\vec{\delta}}$ & $\begin{array}{c}\tilde{o} \\
\text { ì }\end{array}$ & $\begin{array}{l}\bar{\sigma} \\
i\end{array}$ \\
\hline$\pi$ & م & $\pi$ & م & $\sigma$ & م & $\sigma$ & م & $\pi$ & م & $\pi$ & م & \begin{tabular}{|l|l|l|}
$\pi$ & 0
\end{tabular} & & & & \\
\hline 㝴 & & 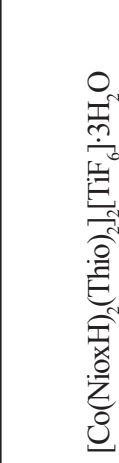 & & & 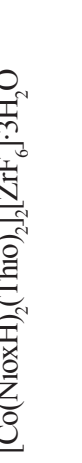 & 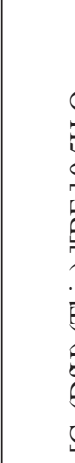 & ?. & 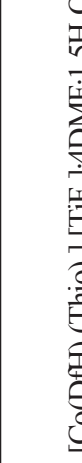 & 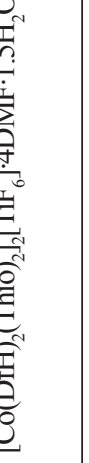 & & 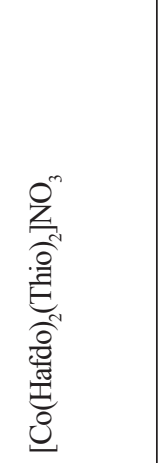 & 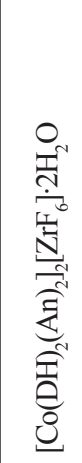 & 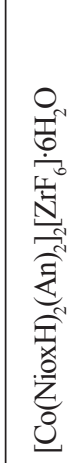 & 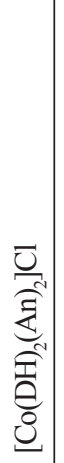 & 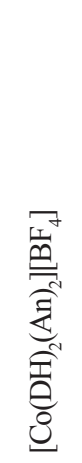 & 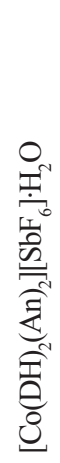 \\
\hline
\end{tabular}


As axial ligands, the molecules of thiocarbamide (containing $\mathrm{NH}_{2}$ group which are able to build H-bonds network) and aniline molecule (whose $\mathrm{NH}_{2}$ group involved in H-bonds network cannot influence molecule orientation), have been selected. For comparison, we used compounds synthesized by us and compounds selected from the Cambridge Crystallographic Data Centre. The emphasis in this study was made on the analysis of Co-S bonds lengths, the deviation of the central atom from the N4 plane, the orientation of axial ligands with respect to the equatorial plane in the complex cation, hydrogen bonds formed by axial ligands and $\pi-\pi$ interactions of the complex, the number of solvent molecules incorporated in the crystal lattice, the volume and nature of the anion of the external sphere.

In the literature, there are known enough Co(III) dioximates which contain on the axial coordinate molecules of thiocarbamide with different orientations with respect to equatorial plane. The authors of these works explain the position of the respective molecules as being due to the formation of multiple hydrogen bonds of axial ligands with the external anions and solvent molecules. Hydrogen bonds are very important for crystal packing, especially considering that in some cases, as it was observed in $\left[\mathrm{Co}(\mathrm{NioxH})_{2}(\mathrm{An})_{2}\right]\left[\mathrm{ZrF}_{6}\right] \cdot 6 \mathrm{H}_{2} \mathrm{O}$ (where NioxH is monoanion of 1,2-cyclohexanedionedioxime and An - aniline) [44], the crystallization water molecules and external anions form a supramolecular H-bonds system. All anions used in this study are able to form hydrogen bonds because of the high electronegativity of atoms, which they contain.

In this study, we were taking into account both the surroundings of the axial ligands and the position of the anion from the external sphere with respect to these ligands. All necessary parameters for discussion regarding the influence of the external factors to orientation of axial ligands have been summarized in table 1.

Studying the dioximate $\left[\mathrm{Co}(\mathrm{DH})_{2}(\mathrm{Thio})_{2}\right] \mathrm{NO}_{3}$ [33] which contains the axially coordinated thiocarbamide molecules, and the $\mathrm{NO}_{3}^{-}$anion in the external sphere, it was observed that the cation is centrosymmetric with the same arrangement of thiocarbamide molecules. The orientation of the molecules is performed by intermolecular hydrogen bonds with the anion from the external sphere (two of these), oxygen of the oxime group from the neighboring complex cation and an intramolecular hydrogen bond with oxygen of the equatorial oxime group. All donor-acceptor atoms involved in these hydrogen bonds are practically in the same plane. Therefore, we considered that these are responsible for the orientation of thiocarbamide molecules with an angle of $70^{\circ}$. The length of $\mathrm{Co}-\mathrm{S}$ bonds in this compound is of $2.292 \AA$. This value was found in the case of three dioximates with different inorganic anions where the complex cation is centrosymmetric, and the orientation of thiocarbamide molecules is almost perpendicular to the equatorial plane $\mathrm{N}_{4}$ (in the studied dioximates the $\mathrm{Co}-\mathrm{S}$ bond varies in the range of $2.278-2.329 \AA$ ). The almost perpendicular orientation excludes the possibility of $\pi$-interactions of thiocarbamide fragment with the dioxime ring current. The absence of solvent molecules in the crystal lattice is attributed to the compact arrangement of ions within the crystal so as the free space which may hold the solvent molecules are missing. In the case of $\left[\mathrm{Co}(\mathrm{DH})_{2}(\mathrm{Thio})_{2}\right] \mathrm{CF}_{3} \mathrm{SO}_{3}[34]$ complex, even if the composition of molecules are similar to the previous one, major changes are observed in the axial ligands position. It is necessary to mention that in the fluorine-containing anion $\mathrm{CF}_{3} \mathrm{SO}_{3}^{-}$, the $\mathrm{CF}_{3}$ group behaves as a $\mathrm{CH}_{3}$ group and it is not H-bonded. For this compound, the complex cation isn't anymore symmetric and the thiocarbamide molecules are oriented differently with respect to the equatorial plan $\mathrm{N}_{4}$. In the case of parallel orientation, the thiocarbamide molecule is "held" in this position through four intermolecular hydrogen bonds, two with anions from external sphere $(2.820,2.896 \AA)$ and two with the oxygen atoms of oxime groups of the neighboring complex cations $(2.845,2.955 \AA)$. This type of orientation involves also the $\pi$-interaction between the fragment of thiocarbamide and dioxime ring current $(2.999 \AA)$. In the case of perpendicular orientation, the thiocarbamide fragment is H-bonded with the anions from the external sphere and a bifurcated intramolecular hydrogen bond with the oxime group oxygens also has been observed. Even though the $\mathrm{CF}_{3} \mathrm{SO}_{3}^{-}$anion is bigger than $\mathrm{NO}_{3}^{-}$, a reason that should increase the possibility of the incorporation of solvent molecules in the crystal lattice, in this complex they are also missing.

The crystalline structure of $\left[\mathrm{Co}(\mathrm{DH})_{2}(\mathrm{Thio})_{2}\right]_{2}\left[\mathrm{BeF}_{4}\right] \cdot \mathrm{C}_{2} \mathrm{H}_{5} \mathrm{OH}$ [35] complex differs from the previous one, due to the fact that a molecule of ethanol participates at packing, which create a disordering for $\left[\mathrm{BeF}_{4}\right]^{2-}$ anion. However, the orientation of thiocarbamide molecules with respect to the equatorial plane is similar with the former one, including the number of hydrogen bonds that the thiocarbamide molecules form: the molecule of parallel thiocarbamide with respect to $\mathrm{N}_{4}$ equatorial plane forms 4 hydrogen bonds, two with oxygen atoms from the oxime groups of the neighboring complex cations and two with anions from external sphere or with the anion and the molecule of ethanol; the perpendicular oriented molecule - a bifurcated intermolecular hydrogen bond with the oxime groups oxygens and two hydrogen bonds with the anions from the external sphere or with the anion and the ethanol molecule. The crystal of $\left[\mathrm{Co}(\mathrm{DH})_{2}(\mathrm{Thio})_{2}\right]_{2}\left[\mathrm{SiF}_{6}\right] \cdot 2 \mathrm{H}_{2} \mathrm{O}$ $\cdot \mathrm{C}_{2} \mathrm{H}_{5} \mathrm{OH}[36]$ compound contains two crystallographically independent complex cations. In the complex cation a, both thiocarbamide molecules are oriented almost perpendicularly with respect to the equatorial plane $\mathrm{N}_{4}$. The dihedral angle is $87.21^{\circ}$ and this thiocarbamide forms an intramolecular hydrogen bond with the oxygen atom from the oxime groups and three hydrogen bonds with the fluorine atoms. The thiocarbamide with the dihedral angle $75.98^{\circ}$ forms a bifurcated intra- and intermolecular hydrogen bond with the oxime group oxygens, a hydrogen bond with the oxygen from the 
neighboring cation, a bifurcated hydrogen bond with fluorine atoms and a hydrogen bond with the oxygen atom of the ethanol molecule.

In both cases, the possibility of $\pi$-interaction between the thiocarbamide fragment and dioximic ring current is excluded. Atoms, donors and acceptors, which participate to these hydrogen bonds, are practically planar excluding the oxygen atom of the ethanol molecule and one of the fluorine atoms which participates to a bifurcated hydrogen bond.

These atoms are within a distance of $1.5 \AA$ with respect to the average plan of other donoracceptor atoms. In the complex cation $\mathbf{b}$ the thiocarbamide molecules are oriented differently (parallel and perpendicular) with respect to the equatorial plane $\mathrm{N}_{4}$. In the case of perpendicular orientation, the position of thiocarbamide molecule is fixed by an intramolecular H-bond and two hydrogen bonds with fluorine atoms of the anion, and in the case of parallel orientation, thiocarbamide forms two hydrogen bonds with crystallization water molecules and one with the fluorine atom. In addition, parallel orientation allows the formation of $\pi$-interaction between the thiocarbamide fragment and metallocycle.

The $\quad\left[\mathrm{Co}(\mathrm{DH})_{2}(\text { Thio })_{2}\right]_{2}\left[\mathrm{ZrF}_{6}\right] \cdot 2 \mathrm{H}_{2} \mathrm{O} \quad[37]$ compound consists of two complex cations $\left[\mathrm{Co}(\mathrm{DH})_{2}(\mathrm{Thio})_{2}\right]^{+}$, the centro-symmetric anion $\left[\mathrm{ZrF}_{6}\right]^{2-}$ and two crystallographically independent crystallization water molecules. In the complex cation, one thiocarbamide molecule is oriented parallel and the other perpendicularly with respect to the same plane $\mathrm{N}_{4}$. The dihedral angles between the equatorial plane $\mathrm{N}_{4}$ and thiocarbamide molecules planes formed by atoms Co1-S1-C9 and Co2-S2-C10 are of 25.01 and $84.93^{\circ}$, respectively (Fig. 1).

As in the case of other dioximates used in the study, for this compound it was also observed that the thiocarbamide molecule parallel to the equatorial plane is oriented over metallocycle. This fact leads to a $\pi$-interaction between the thiocarbamide fragment and the centre of metallocycle. In the case of the perpendicular thiocarbamide molecule, this is located along the pseudo-heterocycles of six atoms which are formed due to intramolecular hydrogen bonds of the oxime fragments. This orientation allows the formation of intramolecular hydrogen bonds between the $\mathrm{NH}_{2}$ group of thiocarbamide and the oxygen atom of the oxime group. It was also observed for this complex that the hydrogen bonds, in which perpendicular thiocarbamide molecules are involved, are practically in the same plane (Fig. 2).

This fact may contribute essentially to the explanation of the molecules orientation with respect to the equatorial plane $\mathrm{N}_{4}$.

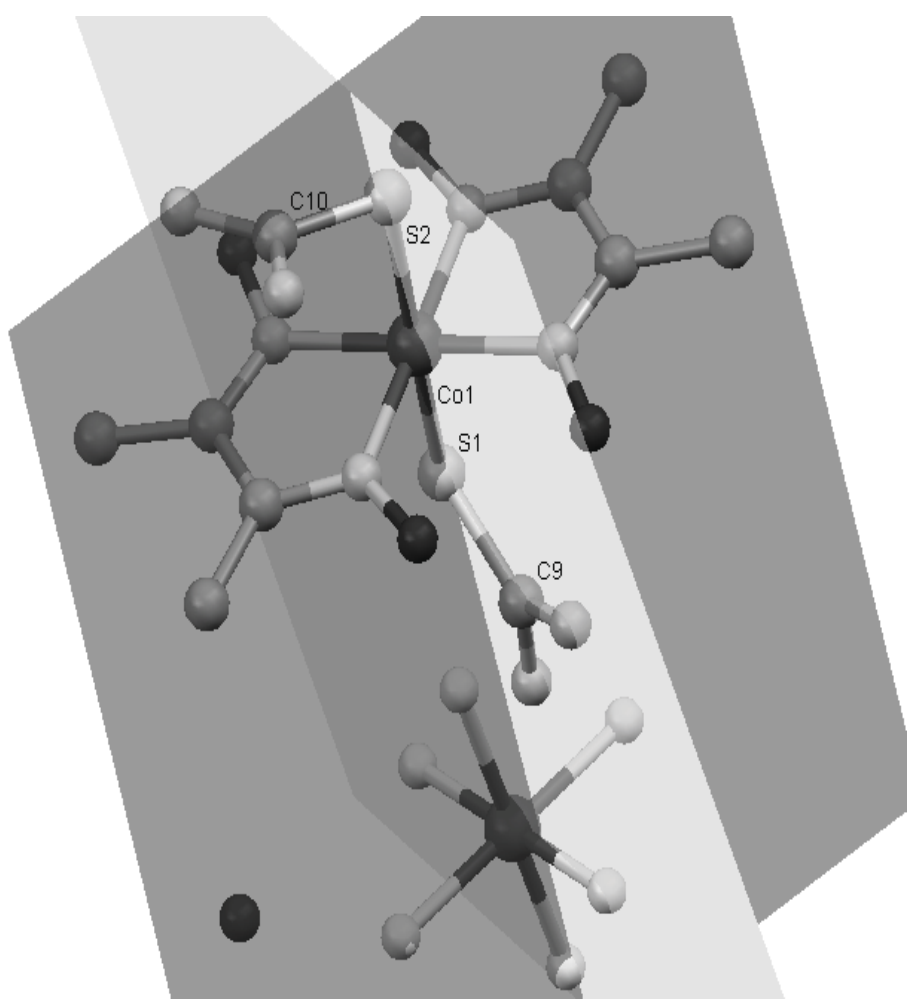

Figure 1. Orientation of the CoSC planes of thiocarbamide molecules with respect to the metallocycle from the equatrial plane in $\left[\mathrm{Co}(\mathrm{DH})_{2}(\mathrm{Thio})_{2}\right]_{2}\left[\mathrm{ZrF}_{6}\right] \cdot 2 \mathrm{H}_{2} \mathrm{O}$.

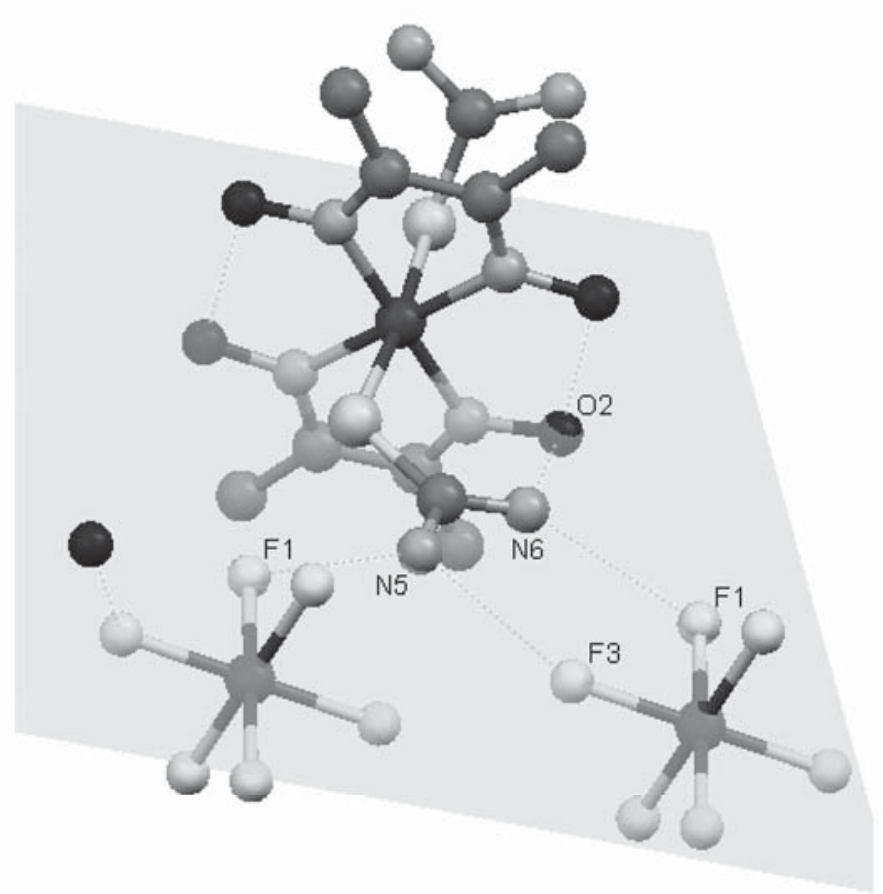

Figure 2. The planarity of hydrogen bonds which contribute to the orientation of thiocarbamide molecules oriented perpendicularly with respect to the equatorial plane $\mathrm{N}_{4}\left[\mathrm{Co}(\mathrm{DH})_{2}(\mathrm{Thio})_{2}\right]_{2}\left[\mathrm{ZrF}_{6}\right] \cdot 2 \mathrm{H}_{2} \mathrm{O}$. 
In the case of parallel orientation the electronegative atoms which are H-bonded aren't located in the same plane but vary from the average plane formed by all these electronegative atoms in the limits of $0.083-1.366 \AA$. The oxygen atom of the water molecule is the most out of this plane. However, the parallel orientation is mostly supported by the $\pi-\pi$ interaction, which in this case is equal to approximately $3 \AA$, and hydrogen bonds are just reinforcing this position. Also, it worth to note that the thiocarbamide molecule oriented perpendicularly is not H-bonded to the crystallization water molecules. These water molecules are located in the vicinity of the parallel oriented thiocarbamide.

The complex compound $\left[\mathrm{Co}(\mathrm{D})\left(\mathrm{DH}_{2}\right)(\text { Thio })_{2}\right]_{2}\left[\mathrm{TiF}_{6}\right] \cdot 2 \mathrm{DMF}[38]$ (where $\mathrm{D}$ is bideprotonated dimethylglyoxime) consists of a single crystallographycally independent complex cation. Comparing to previous compounds, in this case the dimethylglyoxime molecules are coordinated in the equatorial plane, one in bideprotonated form and the other unprotonated. The axial thiocarbamide ligands are also oriented differently with respect to the equatorial plane. One thiocarbamide molecule lies at the angle of $14.10^{\circ}$ to the equatorial plane $\mathrm{N}_{4}$, and the other molecule - at the angle of $86.60^{\circ}$. The parallel oriented thiocarbamide molecule is H-bonded with the neighboring electronegative atoms and all $\mathrm{H}$-bonds are practically in the same plane (Fig. 3) as in the case of the perpendicularly oriented thiocarbamide molecule analyzed in the previously complex (Fig. 2).

Hydrogen bonds which are formed by the perpendicularly oriented thiocarbamide molecule slightly differ from the planarity due to DMF molecules which are disordered in the crystal lattice. In this complex, the cations form chains along the $b$ axis based on $\mathrm{NH}_{2}$ groups of the thiocarbamide $\mathrm{H}$-bonded to oxygen of the oxime groups. These chains are linked through $\left[\mathrm{TiF}_{6}\right]^{2-}$ anions which form hydrogen bonds with parallel and perpendicularly oriented thiocarbamide molecules. Therefore, the oriented along the $b$ axis $\left[\mathrm{TiF}_{6}\right]^{2-}$ anions, link around them four similar chains. Molecules of the disordered dimethylformamide are located in the vicinity of the perpendicularly oriented thiocarbamide molecules and are $\mathrm{H}$-bonded to them.

In the crystal structure of $\left[\mathrm{Co}(\mathrm{DH})_{2}(\mathrm{Thio})_{2}\right]_{3}\left[\mathrm{AlF}_{6}\right] \cdot 2 \mathrm{H}_{2} \mathrm{O}[39]$, two crystallographically independent complex cations are present and one of them is centrosymmetric. In the centrosymmetric cation a thiocarbamide molecules lies at the angle of $85.11^{\circ}$ to the equatorial plane $\mathrm{N}_{4}$ being fixed through 4 hydrogen bonds (one intramolecular, two with the anion and one with the neighboring cation). In the complex cation $\mathbf{b}$ thiocarbamide molecules are oriented both perpendicularly and parallel. In the case of perpendicular orientation, the thiocarbamide molecule is fixed through three hydrogen bonds (one intramolecular with the oxygen atom of the oxime group and two intermolecular with fluorine atoms of the anion).

The almost parallel orientation of the molecule B is caused by the formation of two hydrogen bonds (one with the crystallization water molecule and one with the fluorine atom of the anion) and a $\pi-\pi$ interaction with the metallocycle of the equatorial plane.

As a result, it was established that when thiocarbamide molecules are oriented parallel and perpendicularly with respect to the equatorial plane $\mathrm{N}_{4}$, the crystallization water molecules are in the vicinity of parallel oriented thiocarbamide molecules and in principle this orientation causes gaps in the crystal lattice suitable for solvent molecules incorporation.

Also, in the majority of these cases, donor and acceptor atoms which participate in the formation of hydrogen bonds and influence the orientation of thiocarbamide molecules are arranged practically in the same plane, and $\pi-\pi$ interactions which appear between the parallel oriented thiocarbamide fragment and the metallocycle of the equatorial plane fix the respective position of the ligand. There have not been encountered so far the cases, where in the symmetric cation the thiocarbamide molecules are oriented

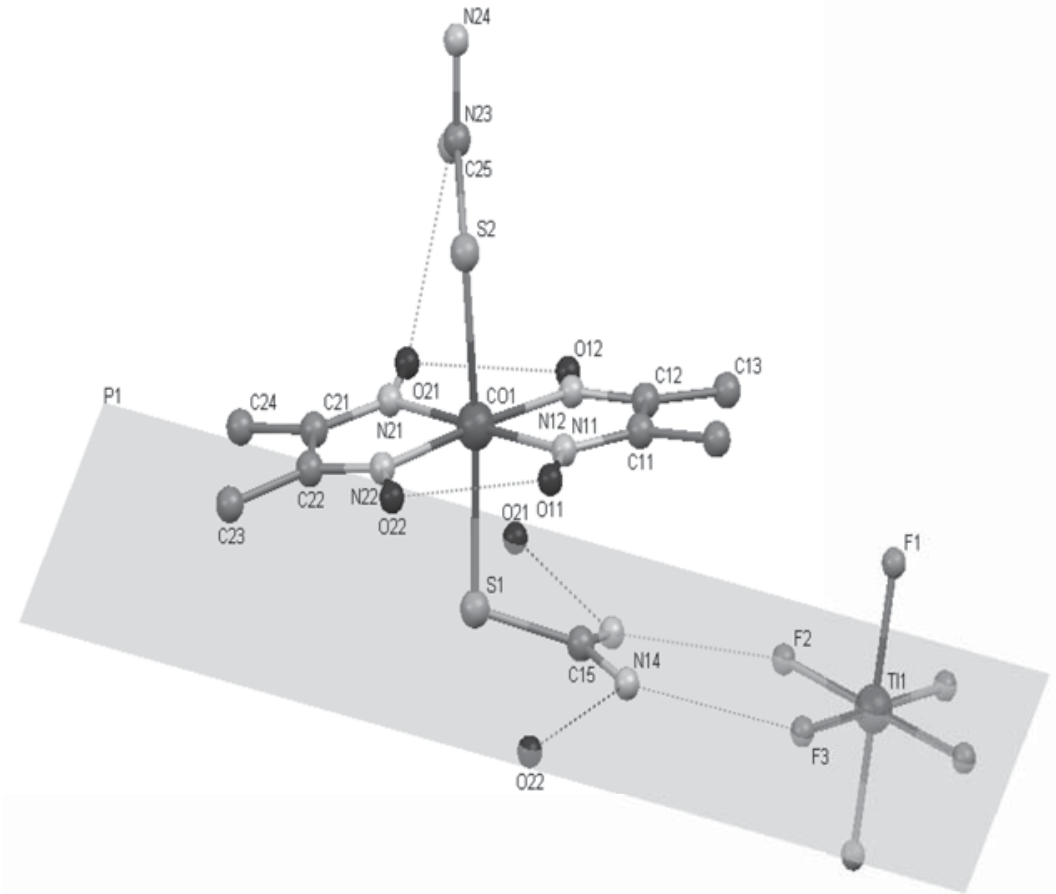

Figure 3. The planarity of hydrogen bonds which contribute to the orientation of thiocarbamide molecules oriented parallel with respect to the equatorial plane $\mathrm{N}_{4}\left[\mathrm{Co}(\mathrm{D})\left(\mathrm{DH}_{2}\right)\left(\mathrm{Thio}_{2}\right]_{2}\left[\mathrm{TiF}_{6}\right] \cdot 2 \mathrm{DMF}\right.$. For clarity, hydrogen atoms are omitted. almost parallel. 
Mostly, they are oriented almost perpendicularly or in some cases - intermediary, such as $\left[\mathrm{Co}(\mathrm{DfH})_{2}(\mathrm{Thio})_{2}\right]$ $\left[\mathrm{BF}_{4}\right] \cdot 0,5 \mathrm{H}_{2} \mathrm{O}$ (where DfH is monoanion of diphenylglyoxime) [35] and [Co(NioxH) $\left.{ }_{2}(\mathrm{Thio})_{2}\right]_{2}\left[\mathrm{SiF}_{6}\right][41]$ complexes (Table 1). Besides the fact that the parallel orientation of thiocarbamide molecules in the cation and the presence of crystallization water molecules are interdependent, it was established that in the case of complexes $\left[\mathrm{Co}(\mathrm{NioxH})_{2}\left(\mathrm{Thio}_{2}\right]_{2} \mathrm{SO}_{4} \cdot 2 \mathrm{H}_{2} \mathrm{O}\right.$ [40], $\left[\mathrm{Co}(\mathrm{NioxH})_{2}(\mathrm{Thio})_{2}\right]_{2}\left[\mathrm{SiF}_{6}\right] \cdot 3 \mathrm{H}_{2} \mathrm{O}[42]$ and $\left[\mathrm{Co}(\mathrm{NioxH})_{2}(\mathrm{Thio})_{2}\right]_{2}\left[\mathrm{SiF}_{6}\right]$, the orientation of thiocarbamide molecules is different, all compounds contain pairs of crystallographically independent complex cations. In the first compound, thiocarbamide molecules are oriented almost parallel in the cation a and mixed (perpendicular and parallel) in cation b. In cation a of the second compound, molecules are almost parallel and perpendicular, in cation $\mathbf{b}$ - intermediate and parallel, and in the third compound, where a crystallization water molecule is missing, thiocarbamide molecules in the cation $\mathbf{a}$ are oriented intermediate $\left(47.58^{\circ}\right)$, and in cation $\mathbf{b}$ - perpendicularly $\left(81.60^{\circ}\right)$.
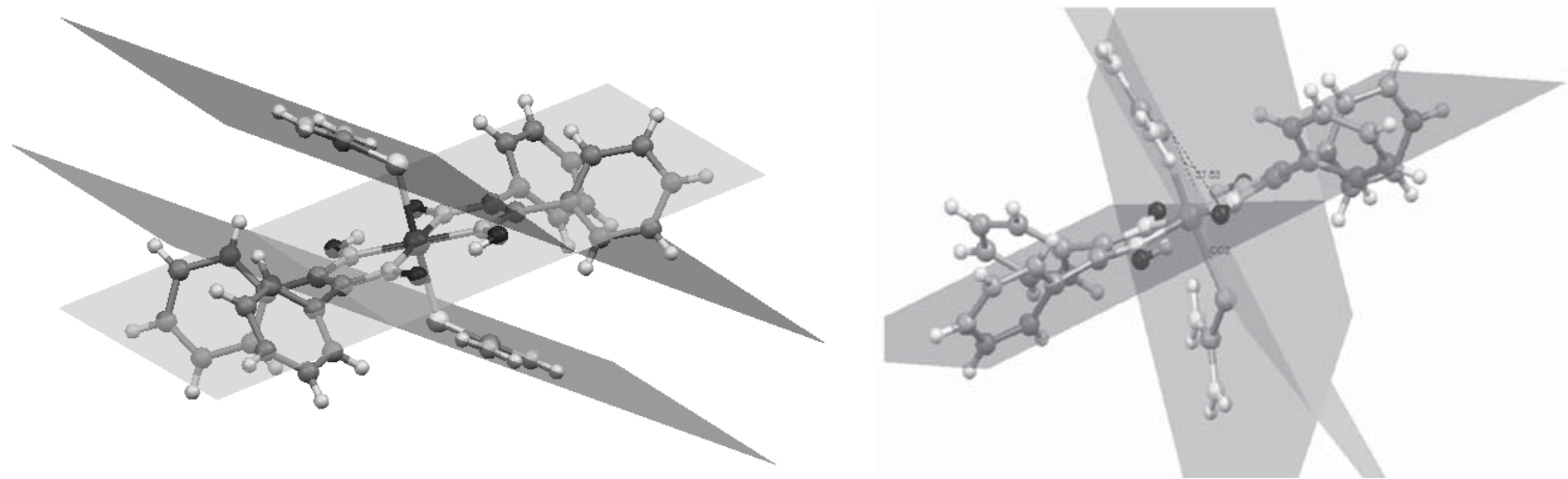

Figure 4. Orientation of thiocarbamide molecules in the complex cation A (left) and B (right) of $\left[\mathrm{Co}(\mathrm{DfH})_{2}(\mathrm{Thio})_{2}\right]_{2}\left[\mathrm{TiF}_{6}\right] \cdot 3.5 \mathrm{DMF} \cdot 1.5 \mathrm{H}_{2} \mathrm{O}$.

In these compounds it wasn't observed for water molecules to form hydrogen bonds with the thiocarbamide oriented perpendicularly with respect to the equatorial plane $\mathrm{N}_{4}$. Even though some crystallization water molecules do not participate directly in the formation of hydrogen bonds with thiocarbamide molecules, however, they are located in the space created by the parallel oriented thiocarbamide.

In table 1 are presented two compounds which contain in the equatorial plane of the complex cation diphenylglyoxime and thiocarbamide as the axial ligand. From this table it can be observed that thiocarbamide molecules are oriented intermediary and almost perpendicular to the equatorial plane and a parallel orientation of these ligands were not observed. The parallel orientation of the thiocarbamide molecules probably is not aleatory, but is conditioned by its

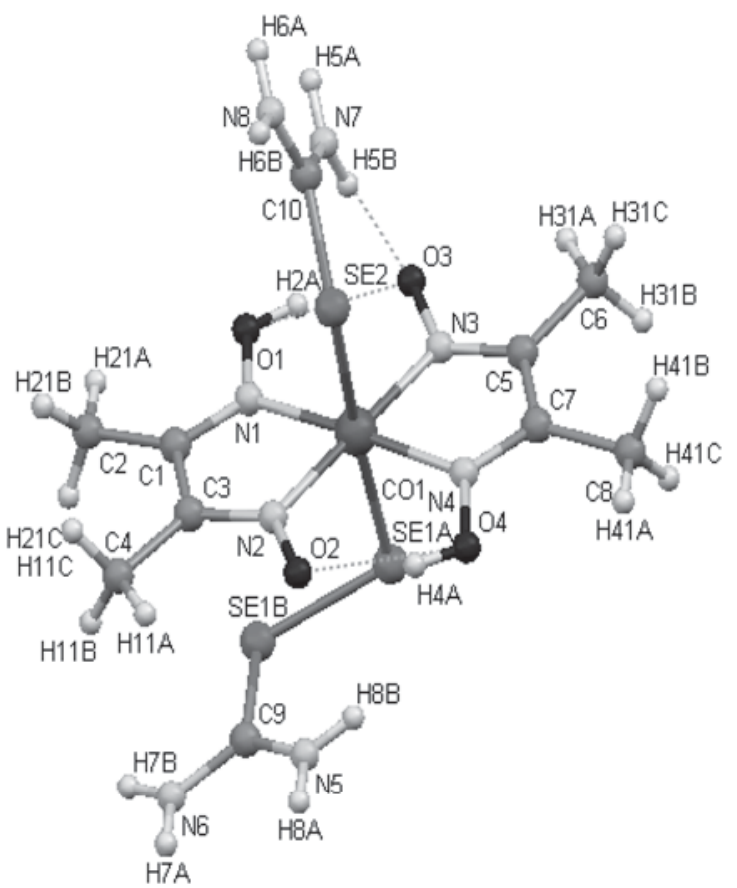

Figure 5. Complex cation in $\left[\mathrm{Co}(\mathrm{DH})_{2}(\mathrm{Seu})(\mathrm{Se}-\mathrm{Seu})\right]\left[\mathrm{ZrF}_{6}\right] \cdot 3 \mathrm{H}_{2} \mathrm{O}$. intermolecular H-bonds. In both cases there is a pair of complex cations crystallographically independent where, in the complex cation thiocarbamide molecules are oriented parallel to each other and in the other the dihedral angle between the plains of these molecules is equal to approximately $38^{\circ}$ (Fig. 4). Also, in these compounds, solvent molecules from the crystal lattice may form hydrogen bonds with molecules which are located in the perpendicular position with respect to equatorial plane $\mathrm{N}_{4}$. This can be explained by the fact that dioxime fragments in this case being more voluminously create greater possibilities of crystallization of solvent molecules even in the vicinity of thiocarbamide molecules perpendicularly oriented.

The study of Co(III) dioximates which contain in the axial plane molecules of selenourea, allowed to obtain the crystalline structure of two compounds of this type [48]. The X-ray investigations showed that synthesis triggered some chemical transformations forming a new unusual ligand Se-Seu. In this case, molecules of selenourea and Se-Seu are located in the axial plane. In both cases, molecules of SeSeu are oriented parallel to the metallocycle of the 
equatorial plane forming $\pi$ - $\pi$ interactions between the uncoordinated atom of selenium and the $\pi$-delocalized system of the metallocycle of the equatorial plane. Selenourea molecules are oriented approximately perpendicular with respect to the equatorial plane with the formation of an intramolecular hydrogen bond with the oxygen from the oxime group (Fig. 5). Atoms which participate in the formation of hydrogen bonds both with Seu and Se-Seu are located approximately in the same plane as in the case of Co(III) dioximates which contain in the equatorial plane thiocarbamide molecules.

Three new compounds, with the molecular formulae $\left[\mathrm{Co}(\mathrm{DH})_{2}\left(\mathrm{Thio}_{2}\right]\left[\mathrm{Rh}(\mathrm{Thio})_{6}\right]\left[\mathrm{BF}_{4}\right]_{4}(\right.$ Fig. 6$),\left[\mathrm{Co}(\mathrm{DH})_{2}(\mathrm{Thio})_{2}\right]$ $\left[\mathrm{Rh}(\mathrm{Thio})_{6}\right]\left[\mathrm{TiF}_{6}\right]_{2} \cdot \mathrm{H}_{2} \mathrm{O}$ and $\left[\mathrm{Co}(\mathrm{NioxH})_{2}(\mathrm{Thio})_{2}\right]_{2}\left[\mathrm{Rh}(\mathrm{Thio})_{5} \mathrm{Cl}\right]\left[\mathrm{TiF}_{6}\right]_{2} \cdot 4 \mathrm{H}_{2} \mathrm{O}$ were synthesized and studied by using different physical methods of analysis [49]. They represent new ionic structures, each of them having in their composition two types of complex cations based on octahedrally coordinated $\mathrm{Co}$ (III) and $\mathrm{Rh}$ (III). In all these three compounds, the coordination of $\alpha$-dioximes to $\mathrm{Co}$ (III) and of thiocarbamide to $\mathrm{Rh}(\mathrm{III})$ with the formation of distinct complex cations was observed.

In the case of these compounds thiocarbamide molecules from complex cations $\left[\mathrm{Co}(\mathrm{DH})_{2}(\mathrm{Thio})_{2}\right]^{+}$are oriented from intermediary to perpendicular position with respect to the equatorial plane (the angle between the fragment of thiocarbamide and equatorial plane is in the range of $62-65^{\circ}$ ) forming intramolecular hydrogen bonds with the oxygen atom of the oxime group. In the $\left[\mathrm{Co}(\mathrm{NioxH})_{2}(\mathrm{Thio})_{2}\right]_{2}\left[\mathrm{Rh}(\mathrm{Thio})_{5} \mathrm{Cl}\right]\left[\mathrm{TiF}_{6}\right]_{2} \cdot 4 \mathrm{H}_{2} \mathrm{O}$ compound two crystallographically independent complex cations $\left[\mathrm{Co}(\mathrm{NioxH})_{2}(\text { Thio })_{2}\right]^{+}$are present.

In the cation $\mathrm{B}$ the thiocarbamide molecules are oriented with respect to the equatorial plane $\mathrm{N}_{4}$ in the same way to that of the similar dioximes, with dihedral angles of $\sim 56^{\circ}$. Therefore, intramolecular hydrogen bonds between $\mathrm{NH}_{2}$ group and oxygen atom from the oxime group are formed. In the case of cation A, the orientation of thiocarbamide molecules differs as compared to previous cations, dihedral angles between those planes are equal to 30.53 and $35.17^{\circ}$, respectively.

In the complex cations $\left.[\mathrm{Rh} \text { (Thio) })_{6}\right]^{3+}$ it was observed that each pair of trans thiocarbamide molecules are oriented differently to the plane $\mathrm{S}_{4}$ which belong to the sulfur atoms of the other thiocarbamide molecules, angles varying in the range $70-85^{\circ}$. In the case of these cations, a $\mathrm{NH}_{2}$ group of thiocarbamide molecule forms an intramolecular hydrogen bond with the sulfur atom of the neighboring molecule (Fig. 6). The cations are linked between them through external fluor-containing anions which form a complicated hydrogen bonds network.
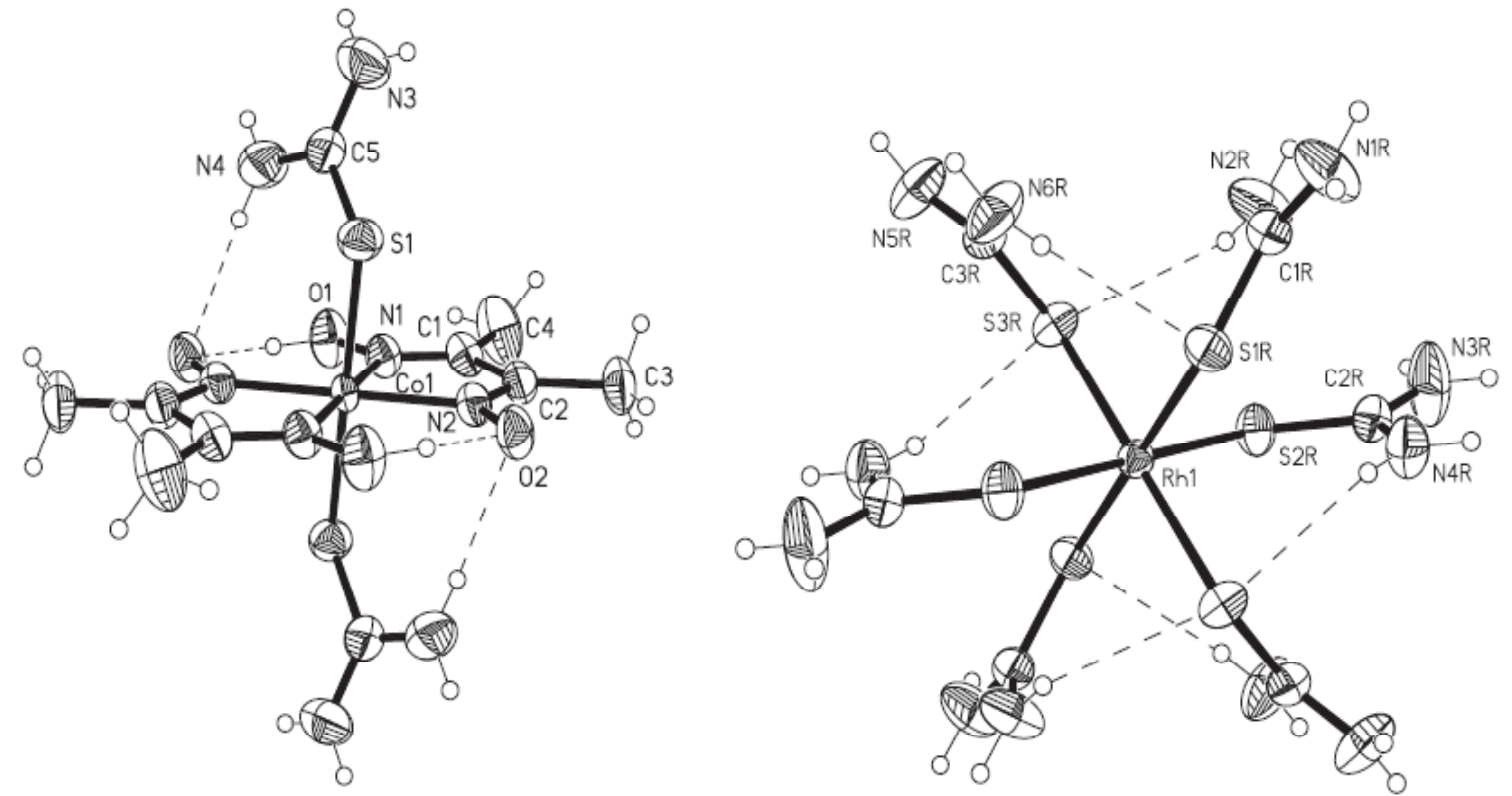

Figure 6. ORTEP drawing of the complex cations $\mathrm{Co}(\mathrm{III})$ and $\mathrm{Rh}(\mathrm{III})$ of $\left[\mathrm{Co}(\mathrm{DH})_{2}(\mathrm{Thio})_{2}\right]\left[\mathrm{Rh}\left(\mathrm{Thio}_{6}\right]_{[}\left[\mathrm{BF}_{4}\right]_{4}\right.$ with the numbering scheme.

In the case of these complex cations, a tendency of planar arrangement of hydrogen bonds formed between $\mathrm{NH}_{2}$ groups of the thiocarbamide molecules and surrounding electronegative atoms was observed. It was also established that anions from the external sphere contribute essentially to the stability of crystalline structure through numerous hydrogen bonds in which these anions participate.

An analysis of complexes which contain aniline molecules in apical position established that these are oriented almost parallel to the equatorial plane $\mathrm{N}_{4}$ forming $\pi-\pi$ interactions between the centers of metallocycles and phenyl rings. Aniline molecules do not contain functional groups which could cause a different orientation of these ligands through the formation of hydrogen bonds $\left(\mathrm{NH}_{2}\right.$ group of the aniline molecule is coordinated to the central atom and does not 
influence in any case the steric factor of the benzene ring, and for this reason it was excluded from the study). However, besides $\pi-\pi$ interactions which are formed between the benzene ring and the metallocycle of the equatorial plane, in some cases week hydrogen bonds such as $\mathrm{C}-\mathrm{H} \cdots \mathrm{F}$ or $\mathrm{C}-\mathrm{H} \cdots \mathrm{O}$ were observed [44].

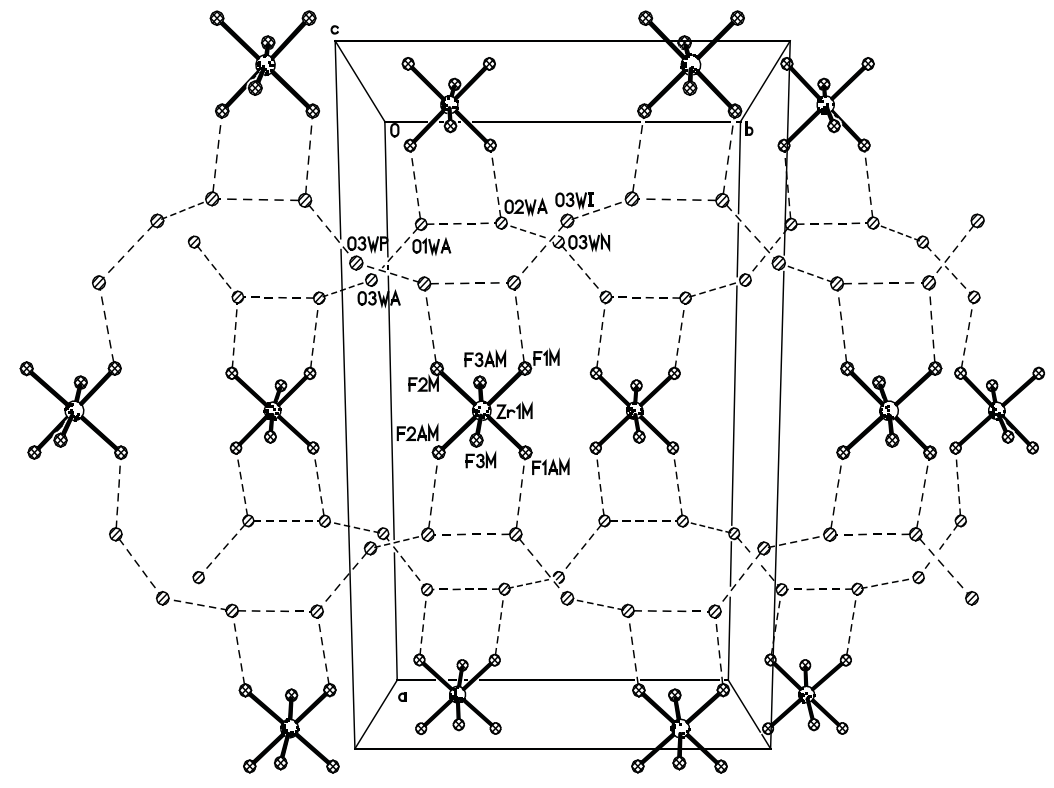

Figure 7. Supramolecular system formed by external fluor-containing anions and crystallization water molecules viewed along the $[001]$ direction in $\left[\mathrm{Co}(\mathrm{NioxH})_{2}(\mathrm{An})_{2}\right]_{2}\left[\mathrm{ZrF}_{6}\right] \cdot 6 \mathrm{H}_{2} \mathrm{O}$.

For some compounds as $\left[\mathrm{Co}(\mathrm{NioxH})_{2}(\mathrm{An})_{2}\right]_{2}\left[\mathrm{ZrF}_{6}\right] \cdot 6 \mathrm{H}_{2} \mathrm{O}[44]$ it was observed that anions and water molecules form their own supramolecular system under a complicated system of hydrogen bonds (Fig. 7).

In the case of dioximates which contain aniline molecules the length of Co-N bonds doesn't vary as much as in the case of dioximates with thiocarbamide. Interdependence between the orientation of molecules from apical position and the deviation of cobalt atom from the plane $\mathrm{N}_{4}$ hasn't been found yet. As consequence, the anion from the external sphere and solvent molecules influence the orientation of aniline molecules with respect to the equatorial plane $\mathrm{N}_{4}$ in a lesser extent than thiocarbamide molecules in $\mathrm{Co}$ (III) dioximes. The same is observed in the case of $\mathrm{Co}$ (III) dioximates which contain in the axial positions molecules of sulfanilamide. The latter are oriented approximately parallel to the

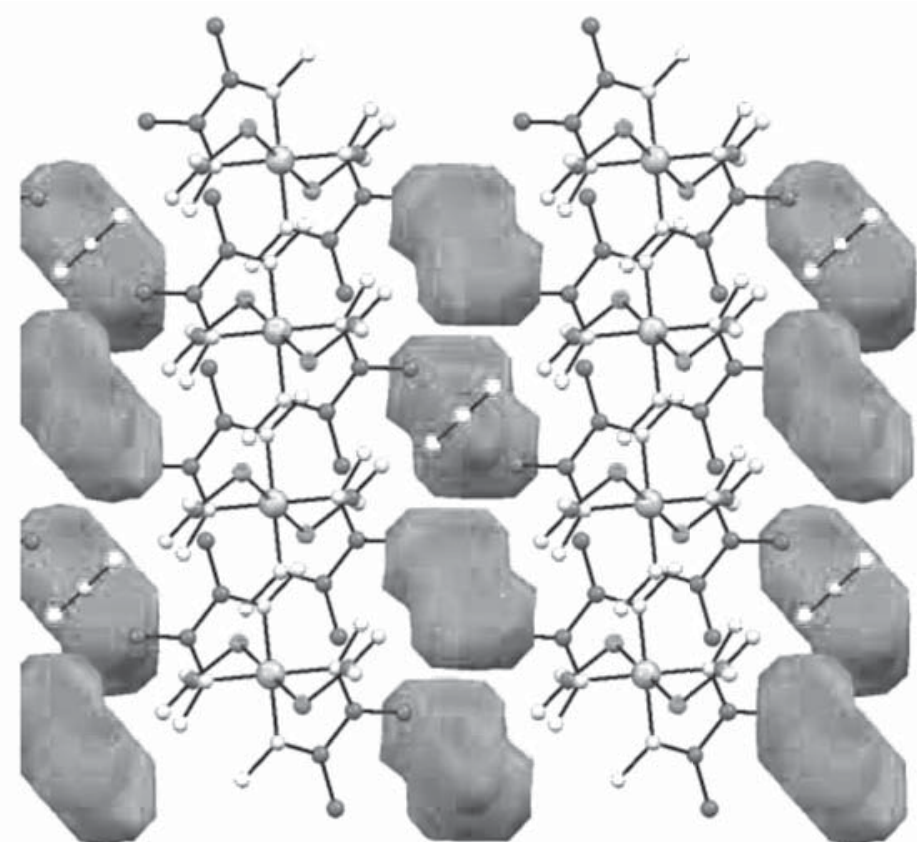

Figure 8. Packing in the crystal lattice of the complex $\left[\mathrm{Co}(\mathrm{DH})_{2}(\mathrm{Thio})_{2} \mathrm{NO}_{3}\right.$. metallocycle of the equatorial plane (angles formed by the respective planes are in the range of $25-28^{\circ}$ ) also forming $\pi-\pi$ interactions between the aromatic ring of sulfanilamide and the $\pi$-delocalized system of metallocycle. Although sulfanilamide contains a $\mathrm{NH}_{2}$ group, it does not contribute to the orientation of the respective molecule. However, it participates in the formation of intermolecular hydrogen bonds contributing to the stability of the crystalline structure [50].

The ability of crystal packing is confirmed by the presence of voids in the crystal lattice. For this class of compounds the formation of voids in the crystal lattice is not usual. Almost all the combinations of the studied complexes in this article don't contain cavities. Only for three complexes voids were identified, the largest being in the $\left[\mathrm{Co}(\mathrm{DH})_{2}(\mathrm{Thio})_{2}\right] \mathrm{NO}_{3}$ complex [33] (Fig. 8), cavities forming $124.3 \AA^{3}(5,7 \%)$ of the crystal volume. Usually, more voluminous ligands are required. Sulfanilamide could contribute to the formation of these cavities. The distance between $\mathrm{NH}_{2}$ groups in sulfanilamide is 
equal to $\sim 7,6 \AA$. However, even in the case of coordination compounds which contain sulfanilamide as axial ligands these cavities are not formed. In the case of compounds with sulfanilamide, as it was mentioned, the planes of aromatic rings of the respective ligand are oriented under an angle smaller than $28^{\circ}$ with respect to the metallocycle of the equatorial plane giving the possibility to form $\pi$-interactions with the dioxime ring current.

The cations are arranged tightly (Fig. 9) and linked by hydrogen bonds forming a pseudo-polymer chains that excludes any possibility to form cavities in the crystal lattice. Even in the case when solvent molecules are removed from the crystal lattice, the volume of obtained cavities does not exceed $10 \%$.

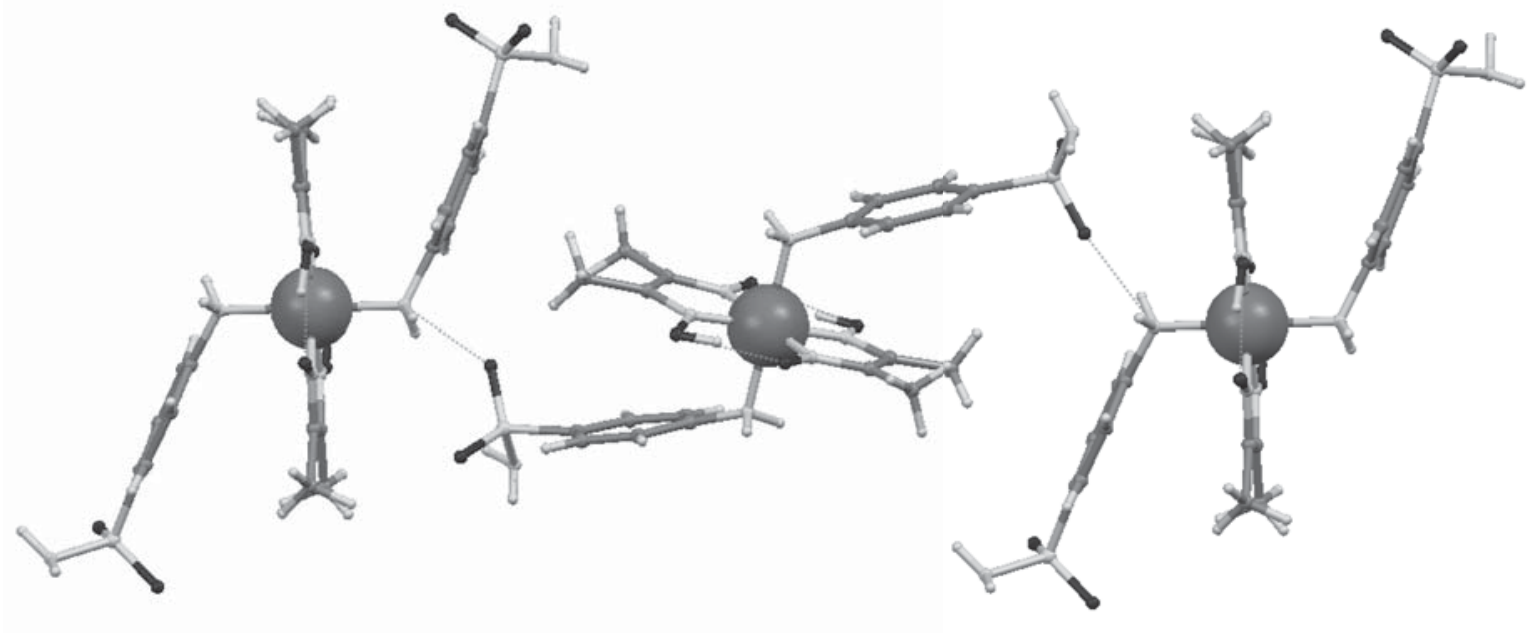

Figure 9. Arrangement of cations whithin the crystal of $\left[\mathrm{Co}(\mathrm{DH})_{2}(\mathrm{Sam})_{2}\right]_{2}\left[\mathrm{ZrF}_{6}\right] \cdot 5 \mathrm{H}_{2} \mathrm{O}$.

Therefore, it can be assumed that these complexes cannot be treated as porous substances. Instead, as a general result of our research it was found that these complexes can be successfully used as biostimulators of some enzymogenetic processes in some strains of fungi as Aspergillus niger 33 CNMN FD 06A, Aspergillus niger 33-19 CNMN FD 02A, Rhizopus arrhizus F67 and Rhizopus arrhizus Fischer CNMN FD 03L etc. Also it was found that for some fungi the complexes that contain sulfanilamide as axial ligands reduce the technologic cycle to 48 hours which represent about $33 \%$ of total period.

\section{Conclusions}

In the case of complexes which contain thiocarbamide and selenourea, the orientation of these molecules in the axial plane is conditioned by hydrogen bonds formed with the external sphere anions, vicinal complex cations, solvent molecules, intramolecular hydrogen bonds with oxygen from the oxime group and $\pi-\pi$ interactions with the metallocycle from the equatorial plane.

The hydrogen bonds which contribute to the orientation of thiocarbamide and selenourea molecules in most of the cases are located in the same plane, being responsible for the steric factor of these molecules. Thiocarbamide and selenourea molecules oriented approximately parallel are influenced by $\pi-\pi$ interactions between the respective fragment and the metallocycle of the equatorial plane as well.

The parallel thiocarbamide and selenourea molecules are oriented along the metallocycle of the equatorial plane, while molecules oriented perpendicularly are located in the direction of intramolecular hydrogen bond formed by oxime fragments.

In some coordination compound the fluor-containing anions and solvent molecules, can form their own supramolecular system of hydrogen bonds, which essentially contributes to stability of these compounds. This is one more evidence that external fluorine-containing anions play an important role at the crystal packing.

The solvent molecules incorporated in the crystal lattice, are located in the vicinity of thiocarbamide or selenourea molecules oriented parallel, some of them forming hydrogen bonds directly with the $\mathrm{NH}_{2}$ group. In the case of oxime radicals, which are more voluminous as diphenylglyoxime, solvent molecules can be located in the vicinity of thiocarbamide and selenourea molecules perpendicularly oriented as well.

In the case of axial ligands such as aniline, sulfanilamide, etc., the approximately parallel orientation is more convenient, with the formation of $\pi$ - $\pi$ interactions between the phenyl ring and the $\pi$-delocalized system of the equatorial plane metallocycle. These types of ligands in the majority of the cases are oriented in the direction of the equatorial plane metallocycle.

The molecules within the crystal are arranged in a manner that the cavities from the crystal lattice are practically 
missing due to compact packing. The formation of cavities in the crystal lattice is observed only in a few cases but they do not exceed $6 \%$ of the crystal volume. Therefore, bis-dioximates of $\mathrm{Co}(\mathrm{III})$ from this series cannot be used as porous materials.

\section{References:}

[1] Stamatatos, T.C.; Christou, G. Inorganic Chemistry. 2009, 48, pp. 3308-3322.

[2] Milios, C.J.; Stamatatos, T.C.; Perlepes, S.P. Polyhedron. 2006, 25, pp. 134-194.

[3] Croitor, L.; Coropceanu, E.; Siminel, A.; Fonari, M. Polyhedron. 2013, 60, pp. 140-150.

[4] Follett, A.; McNabb, K.A.; Peterson, A.A. Inorganic Chemistry. 2007, 46, pp. 1645-1654.

[5] Chaudhuri, Ph. Coord. Chem. Rev. 2003, 243, pp. 143-190.

[6] Croitor, L.; Coropceanu, E.B.; Siminel, A.V. et al. CrystEngComm. 2012, 14, pp. 3750-3758.

[7] Akine, S.; Taniguchi, T.; Saiki, T.; Nabeshima, T.J. Am. Chem. Soc. 2005, 127, 2, pp. 540-541.

[8] Bresciani-Pahor, N.; Farcolin, M.; Marzilli, L.G. et al. Coord. Chem. Rev. 1985, 63, pp. 1-125.

[9] Rogaciov, B.G.; Hindekel, M.L. Russ. Chem. Bull. 1969, 1, pp. 141-142. (in russian)

[10] Matcovschii, C.L.; Balan, N.A.; Batyr, D.G. et al. Journ. A.S.M. Life sciences. 1969, 4, pp. 3-5. (in russian)

[11] Matcovschii, C.L. Journ. A.S.M. Life sciences. 1971, 5, pp. 88-89. (in russian)

[12] Matcovschii, C.L.; Bologa, O.A. Globe of Science. 2006, 6, 34-36. (in russian)

[13] Thomas, T.W.; Underhill, A.E. Chem. Commun. 1969, 13, 725a.

[14] Bulhac, I. Sinteza, proprietățile fizico-chimice şi structura compuşilor coordinativi de fier, cobalt, nichel şi cupru cu $\alpha$-dioxime. Teza de doctor habilitat. Chişinău. 2000.

[15] Samus', N.M.; Yushchenko, S.P; Horoshun, I.V. et al. Russ. Journ. Inorg. Chem. 1989, 34, 4, pp. 892-897. (in russian)

[16] Burdinski, D.; Birkelbach, F.; Weyhermuller, T. et al. Inorg. Chem. 1998, 37, pp. 1009-1020.

[17] Voloshin, Y.Z.; Kostromina, N.A.; Kramer, R. Clathrochelates: synthesis, structure and properties. 2002. Amsterdam: Elsevier. 419 p.

[18] Croitor, L.; Coropceanu, E.; Jeanneau, E. et al. Crystal Growth \& Design. 2009, 9, pp. 5233-5243.

[19] Gok, Y.; Yildiz, S.Z. Synthesis and Reactivity in Inorganic and Metal-Organic Chemistry. 1992, 22, pp. 13271341.

[20] Proskina, N.N.; Shafransky, V.N.; Ablov, A.V. Journ. A.S.M. Life sciences. 1968, 6, pp. 7-11. (in russian)

[21] Gulya, A.P.; Rudic, V.F.; Gerbeleu, N.V. et al. Patent №1616111 (USSR).

[22] Bourosh, P.N.; Gerbeleu, N.V.; Gdaniec, M. et al. Russ. Journ. Inorg. Chem. 2006, 51, 2, pp. 309-315. (in russian)

[23] Gărbălău, N.; Simonov, Yu.; Bouroş, P. et al. Patent MD 2833.

[24] Gărbălău, N.; Simonov, Yu.; Deseatnic, A. et al. Patent MD 1203.

[25] Schrauzer, G.N.; Grate, J.H. J. Am. Chem. Soc. 1981, 103, pp. 541-546.

[26] (a) Toscano, P.J.; Brand, H.; Liu, S.; Zubieta, J. Inorg. Chem. 1990, 29, 2101. (b) Ng, F.T.T.; Rempel, G.L.; Mancuso, C.; Halpern, J. Organometallics. 1990, 9, 2762. (c) Brown, T.M.; Cooksey, C.J.; Dronsfield, A.T.; Fowler, J.H. Inorg. Chim. Acta. 1999, 288, 112. (d) Brown, T.M.; Dronsfield, A.T.; Wilkinson, A.S. Inorg. Chim. Acta. 1997, 262, 97. (e) Daikh, B.E.; Finke, R.G. J. Am. Chem. Soc. 1992, 114, 2938.

[27] Bresciani-Pahor, N.; Geremia, S.; Lopez, C. et al. Inorg. Chem. 1990, 29, 1043. (b) Toscano, P.J.; Marzilli, L.G. Prog. Inorg. Chem. 1985, 31, 105. (c) Gilaberte, J.M.; Lo'pez, C.; Alvarez, S. et al. New J. Chem. 1993, 17, 193. (d) Lo'pez, C.; Alvarez, S.; Solans, X.; Font-Altaba, M. Inorg. Chim. Acta. 1986, 111, L19.

[28] Mandal, D.; Gupta, B. D. Organometallics. 2005, 24, pp. 1501-1510.

[29] (a) Clifford, B.; Cullen, W. R. J. Chem. Educ. 1983, 60, 555. (b) Naumberg, M.; Duong, K.N.V.; Gaudemer, F.; Gaudemer, A. C. R. Acad. Sci., Ser. C 1970, 270, 1301. (c) Cabaret, D.; Maigrot, N.; Welvart, Z.; Duong, K. N. V.; Gaudemer, A. J. Am. Chem. Soc. 1984, 106, 2870.

[30] Marzilli, L.G.; Summers, M.F.; Zangrando, E. et al. J. Am. Chem. Soc. 1986, 108, pp. 4830-4838.

[31] Galinkina, J.; Rusanov, E.; Wagner, C. et al. Organometallics. 2003, 22, pp. 4873-4884.

[32] Mandal, D.; Gupta, B.D. Organometallics. 2007, 26, 3, pp. 658-670.

[33] Rusanovskii, M.E.; Samus', I.D.; Proskina, N.N. Izvestya Akademii Nauk Moldavskoi SSR. Seria FizikoTekhnicheskikh i Matematicheskikh Nauk. 1984, 2, pp. 55-57. (in russian)

[34] Gradinaru, J.; Malinovskii, S.; Gdaniec, M.; Zecchin, S. Polyhedron 2006, 25, 17, pp. 3417-3426.

[35] Malinovsky, S.T.; Bologa, O.A.; Coropceanu E.B. et al. Journ. Struct. Chem. 2007, 48, 4, pp. 740-746. (in russian)

[36] Bourosh, P.N.; Coropceanu, E.B.; Simonov, Yu.A. et al. Russ. Journ. Coord. Chem. 2002, 28, 9, pp. 689-697. (in russian)

[37] Malinovsky, S.T.; Coropceanu, E.B.; Bologa, O.A. et al. Journ. Struct. Chem. 2007, 48, 3, pp. 532-538. (in russian) 
[38] Rija, A.; Coropceanu, E.; Bologa, O. et al. Russ. Journ. Inorg. Chem. 2013, 58, 4, pp. 506-516. (in russian)

[39] Bourosh, P.N.; Coropceanu, E.B.; Simonov, Yu.A. et al. Russ. Journ. Inorg. Chem. 2002, 47, 10, pp. 1604-1609. (in russian)

[40] Bourosh, P.N.; Bologa, O.A.; Gdaniec M. et al. Journ. Struct Chem. 2005, 46, 3, 488-493. (in russian)

[41] Bourosh, P.N.; Coropceanu, E.B.; Bologa, O.A. et al. Russ. Journ. Coord. Chem. 2004, 30, 6, pp. 403-409. (in russian)

[42] Simonov, Yu.A.; Gerbeleu, N.V.; Gdaniec, M. et al. Russ. Journ. Coord. Chem. 2001, 27, 5, pp. 368-379. (in russian)

[43] Sakhawat Hussain, M.; Al-Mohdhar, H.M.; Schlemper, E.O. Journal of Crystallographic and Spectroscopic Research. 1989, 19, 1, pp. 77-91.

[44] Rija, A.; Coropceanu, E.; Bologa, O. et al. Journ. Struct. Chem. 2007, 48, 6, pp. 1197-1202. (in russian)

[45] Battaglia, L.P.; Corradi, A.M.; Palmieri, C.G. et al. Acta Cryst. B30, 1974, pp. 1114-1116.

[46] Malinovsky, S.T.; Coropceanu, E.B.; Bologa, O.A.; Bel’sky, V.K. Russ. Journ. Coord. Chem. 2002, 28, 5, pp. 370-376. (in russian)

[47] Coropceanu, E.B.; Rija, A.P.; Lozan, V.I. et al. Russ. Journ. Coord. Chem. 2012, 38, 8, pp. 575-581. (in russian)

[48] Rija, A.P.; Nicolescu, A.; Soran, A. et al. Russ. Journ. Coord. Chem. 2011, 37, 10, pp. 759-767. (in russian)

[49] Bourosh, P.; Coropceanu, E.; Rija, A. et al. Journ. Molec. Struct. 2011, 998, pp. 198-205.

[50] Coropceanu, E.B.; Rija, A.P.; Shafransky, V.N. et al. Journ. Struct. Chem. 2007, 48, 6, pp. 1175-1182. 